\title{
Examining Post-Adoptive Change of Enterprise System Implementations: A Socio-Technical Perspective
}

\author{
Wallayaporn Techakriengkrai \\ New Zealand Parliament \\ wally.techakriengkrai@parliament.govt.nz
}

\section{Angsana A. Techatassanasoontorn}

Auckland University of Technology, New Zealand

Felix B. Tan

Auckland University of Technology, New Zealand

\section{Abstract}

The implementation of a new enterprise system is a major change event for end-users. Since organisations need to modify their processes and structures to align with the enterprise system, users must learn and understand the new system as well as engage with it in their work practices. Past research has largely focused on the initial organisational adoption of an enterprise system. However, there has been little research concerning the change process in the post-adoption stage. This research addresses this gap by drawing on the punctuated sociotechnical information system change (PSIC) model to explain the change through critical events, gaps between socio-technical components, responses to gaps, and outcomes. The research question is: How do socio-technical changes unfold in an enterprise system implementation? The study employs a qualitative interpretive case study method. The results reveal that changes in the structure of work following enterprise system implementation affect organisational performance, the social system, and individual work practices. This research contributes to a better understanding of technical and social changes and their impacts in the post-adoption of enterprise system implementation. The findings may assist organisations in providing appropriate resources and support for successful enterprise system implementation.

Keywords: Enterprise system implementation, socio-technical perspective, post-adoption, qualitative interpretive case study

\section{Introduction}

Enterprise systems (ES) such as Enterprise Resource Planning (ERP), Customer Relationship Management (CRM), and Supply Chain Management (SCM) are generally perceived by users to be complex systems (Wognum et al., 2004). From an organisation's perspective, new enterprise system implementation helps to improve efficiency, effectiveness, and employees' job performance in organisations (Davis, 1993; Dong, 2012). However, the introduction of a new enterprise system tends to require substantial changes in work processes, work practices, relationships between different professional workgroups, roles, skills, and capacities of the system users (Schilhavy \& Iyer, 2007). In a recent survey by Merkle Group Inc. (2018), it was reported that CRM implementation has had a $63 \%$ fail rate. This failure can potentially be attributed to a possible technology misfit and organisations' emphasis on the system itself without the necessary efforts to integrate culture, processes, people, and technology to appropriately manage organisational change (Finnegan \& Currie, 2010; Finnegan \& Willcocks, 
2007; Schwartz, 2002). Lack of appropriate technology use is another important failure factor of enterprise system implementations (Zablah et al., 2004).

Previous research on enterprise systems has largely focused on the initial adoption of enterprise systems and organisational performance (Awasthi \& Sangle, 2012; Chuchuen \& Chanvarasuth, 2011; Hung et al., 2010; Ko et al., 2008; Williams et al., 2017). In contrast, there has been a lack of in-depth analysis that explains changes as a result of ES implementation. Therefore, this study focuses on socio-technical changes associated with the disruptions involved in a new ES implementation in an organisation. The main research question guiding this study is: How do socio-technical changes unfold in an enterprise system implementation?

This study focuses on the post-adoption of an ES, specifically CRM. In the information system (IS) implementation model, pre-adoption refers to the stage of IS implementation that leads to an adoption decision, while post-adoption refers to the stage of IS implementation after an adoption decision (Karahanna et al., 1999). The pre-adoption stage explains how individuals develop expectations toward the IS (Veiga et al., 2014). The stage in which users begin to use an IS to support their work after the system has been installed and made accessible to them is regarded as post-adoption (Jasperson et al., 2005).

This research applies the punctuated socio-technical information system change (PSIC) model (Lyytinen \& Newman, 2008) to explain the change process through critical events, gaps between socio-technical components, as well as responses and outcomes. A socio-technical model enables an in-depth analysis of dynamic and multi-level changes at the macro-level (e.g., organisational structure and policy), the micro-level (individuals' work practices), and the social level (e.g., the relationship among individuals) by paying attention to the interactions among socio-technical components. This study adopts a qualitative interpretive case study method using the embedded multiple-case design (Yin, 2003). Three concurrent data analysis activities proposed by Miles and Huberman (1994) were conducted to theorise the change process in three organisations. In the next section, the study's theoretical foundation is discussed with reference to the literature on ES implementation and organisational change. The socio-technical perspective and the PSIC model are also reviewed.

\section{Theoretical Foundation}

\subsection{Enterprise system implementation and organisational change}

Enterprise systems constitute "a suite of integrated software modules and a common database used to help manage a company's human resources, financials, and the service and/or manufacturing processes" (Sawyer \& Southwick, 2002, p. 264). Since enterprise systems are embedded with prescribed business logic, organisations are often required to change their business processes and restructure their organisations to obtain the desirable benefits (Elbanna, 2007; Ignatiadis \& Nandhakumar, 2007; Seethamraju \& Sundar, 2013). Effective ES implementation depends on not only technical, but also several organisational factors such as organisational politics, cultures, environments, structures, routines, and business processes (Schwartz, 2002; Zablah et al., 2004). In addition, social integration, including acceptance from work colleagues and support from management, is crucial to support changes during ES implementation (Aburub, 2015; Elbanna, 2007; Seethamraju \& Sundar, 2013).

ES implementation, in some cases, may unfold in unpredictable ways with unintended consequences (Bloomrosen et al., 2011; Ignatiadis \& Nandhakumar, 2007; Lyytinen et al., 2009; 
Newell et al., 2002; Rollins, 2012; Strong \& Volkoff, 2010; Williams \& Hardy, 2005). For example, Lyytinen et al. (2009) found that the enterprise system institutionalisation process emerges through unanticipated events (e.g., change of project manager, increased competition to attract skilful IT employees, and customer complaints) that significantly affect the outcome. The complexities of ES implementation can lead to several unintended consequences such as workarounds that prevent organisations from gaining better control over their data and operations (Ignatiadis \& Nandhakumar, 2007), misfits of ES processes that lead to reduced efficiency or effectiveness (Strong \& Volkoff, 2010), changes in communication practices, and impact on social relationships (Newell et al., 2002; Rollins, 2012).

Institutional theory, institutional logics, and socio-technical theory have been widely used to investigate information-technology (IT)-enabled organisational change in general and enterprise system-enabled organisational change in particular (Lyytinen et al., 2009; Yoo et al., 2007; Soh \& Sia, 2004). It is important to note that both institutional theory and institutional logics are macro-level (i.e., organisational level) theories and concepts that may not be applicable in the study of micro-level changes at an individual level (i.e., work practices) (Khalil, 1995). It is important to recognise that ES implementation changes and outcomes involve both the technical and social aspects (Aburub, 2015; Elbanna, 2007; Sawyer \& Southwick, 2002). Next, we discuss how the approach that views changes as a socio-technical phenomenon can offer insights to unravel complexities as well as unpredictable and unintended consequences from ES implementations.

\subsection{A socio-technical perspective}

IS change can be characterised as technical and social change (Lyytinen \& Newman, 2008). Leavitt's socio-technical (S-T) system model views an organisational system as a system with four socio-technical components. These components include actors (e.g., project participants and stakeholders) and their characteristics and attributes; tasks which refer to what and how work is accomplished; structure which represents institutionalised rules and arrangements; and technology including hardware, software, and tools (Leavitt, 1964). The four components are interdependent; they affect each other and the change of one component leads to subsequent changes in other components, which helps us better understand the IS change process.

Previous IS research has adopted a socio-technical perspective (Kim et al., 2012; Luna-Reyes et al., 2005; Lyytinen \& Newman, 2008; Lyytinen et al., 2009; McLeod \& Doolin, 2012) to develop an understanding of changes involved in the development and implementation of new IS by highlighting the modification of organisational structures and work processes through the interactions of the four socio-technical components. However, most studies have used a socio-technical system model to study the change process either in individuals or organisations. To obtain richer insights on changes induced by IS implementation, we believe there is a need to explain both the macro-level and the micro-level changes to individuals who constitute an important part of the change process. The multi-level changes allow us to better understand the interaction among individuals, the CRM system, organisations, and the relationship among them to unveil changes in individual adaptation as well as explain changes in an organisation, such as the introduction of new policy related to system use. Therefore, this study draws on Lyytinen and Newman's (2008) PSIC model that was proposed as "a sensitising device to explain complex IS changes" (p. 590). The PSIC model can explain IS changes as a multi-level and punctuated socio-technical change (critical events, gaps, as well 
as responses and outcomes). Organisational change is a construction of a sequence of incremental adaptations and punctuations (Gersick 1991; Lyytinen \& Newman, 2008; Newman \& Robey, 1992).

Building on the premise that IS change is a socio-technical change, the PSIC model characterises socio-technical components as the content and engine of change. In other words, the socio-technical components and their interrelationships are regarded "as the general 'lexicon' for describing generative mechanisms and outcomes associated with the IS change" (Lyytinen \& Newman, 2008, p. 594). From a system perspective, a socio-technical system is in a stable state, where the four components are mutually aligned, and its performance is maintained. An introduction of a new information system such as an ES creates system instability and introduces a gap among socio-technical components (technology, actors, task, structure). The PSIC model offers key concepts to explain the process of IS change and observed outcomes. Critical events, gaps, and responses ${ }^{1}$ are underlying concepts to explain how a change outcome emerges. A critical event is defined as an intended or unintended event that leads to the generation of gaps between socio-technical components. A gap reflects a structural misalignment in a system. It is defined as "any contingency in the system which, if left unattended, will reduce the system's performance and threaten its viability" (Lyytinen \& Newman, 2008, p. 595). Two possible responses to a gap are incremental adaptation and punctuation. An incremental adaptation response exhibits a gradual or stepwise adaptation of one or several components of a system (Lyytinen \& Newman, 2008). A punctuated response exhibits deep structure transformations which fundamentally change the nature of the sociotechnical system. Punctuations reconfigure socio-technical elements and their interactions, and result in sudden or pronounced change(s) (Gersick, 1991; Lyytinen \& Newman, 2008). Four types of outcomes from responses are (1) failed intervention: the system maintains its current misalignment; (2) successful intervention: the system experiences an incremental change to resolve the misalignment; (3) punctuation: the system experiences a radical change to resolve the misalignment; and (4) crisis: the system suffers from new misalignments or further problems. Following the argument of Lyytinen and Newman (2008) that "events have varying impacts on the system state, we must also find out what sort of impact the particular event ... had on the system(s)" (p. 599) and Lyytinen et al.'s (2009) application of the PSIC model, we do not consider punctuation as one of the outcomes in our analysis because it has already been considered in the analysis of response as either incremental or punctuated.

In this study, the PSIC model and its constitutive process components, namely critical events, gaps, as well as responses and outcomes, will be used to guide the analysis of socio-technical changes as a result of CRM implementation. We pay attention to responses and outcomes of gaps in terms of individual work practices, individual work performance, as well as organisational performance in the post-adoption stage of CRM implementation. In the pastadoption stage, IS is available for use in an organisation, users are trained both in the new work processes and the IS, and they are encouraged to commit to continued IS use.

\footnotetext{
${ }^{1}$ Lyytinen and Newman (2008) define an intervention/event as "[a] planned measure taken towards one or more socio-technical elements, or a system as a whole ... to mitigate against or remove an observed gap" (p. 613). To avoid potential confusion with critical events, we refer to these types of events as responses in this study.
} 


\section{Research Methodology}

This research adopted the qualitative interpretive case study method with an embedded multiple-case design to examine organisational change in ES implementation. A multiple-case design is more appropriate than a single case approach because we are not interested in testing the boundaries of well-formed theory or examining an extreme or a unique case. The benefits of adopting a multiple-case design in this study are well aligned with the research aim to identify organisational changes in different types of organisations. The theoretical sampling strategy was adopted to select case studies (Patton, 1990).

The enterprise systems of interest to this study are the Customer Relationship Management (CRM) systems. Research into CRM has largely focused on individual factors that shape initial adoption (Vella et al., 2012; Wu \& Wu, 2005; Zablah et al., 2004) as well as the implementation process and outcomes at the organisational level (Awasthi \& Sangle, 2012; Chuchuen \& Chanvarasuth, 2011; Dong, 2012; Hung et al., 2010; Ko et al., 2008; Sebjan et al., 2014). Few studies have examined post-adoptive changes at both an individual level and an organisational level. For instance, CRM research has paid little attention to individual work routines that may impact organisational change (Jones et al., 2002; Winter \& Nelson, 1982). Table 1 presents the background information of the three organisations.

\begin{tabular}{|c|c|c|c|}
\hline Cases & RC & HP & BI \\
\hline Industry types & $\begin{array}{l}\text { Innovative office } \\
\text { automation solutions }\end{array}$ & Hospital & Insurance \\
\hline No. of employees & Approximately 2,000 & Approximately 1,300 & Approximately 1,400 \\
\hline No. of participants & $\begin{array}{l}6 \text { Users } \\
4 \text { IT support } \\
4 \text { Management }\end{array}$ & $\begin{array}{l}6 \text { Users } \\
1 \text { IT support } \\
4 \text { Management } \\
\end{array}$ & $\begin{array}{l}8 \text { Users } \\
3 \text { IT support } \\
7 \text { Management } \\
\end{array}$ \\
\hline $\begin{array}{l}\text { CRM software package } \\
\text { used }\end{array}$ & Salesforce CRM & Seibel CRM & $\begin{array}{l}\text { Microsoft Dynamics } \\
\text { CRM }\end{array}$ \\
\hline CRM module used & Sales automation & $\begin{array}{l}\text { Marketing automation, } \\
\text { and Customer service }\end{array}$ & $\begin{array}{l}\text { Sales automation, } \\
\text { Marketing automation, } \\
\text { and Customer service }\end{array}$ \\
\hline $\begin{array}{l}\text { Departments } \\
\text { implementing CRM } \\
\text { system }\end{array}$ & $\begin{array}{l}\text { Sales and marketing } \\
\text { department }\end{array}$ & $\begin{array}{l}\text { Local marketing, } \\
\text { Overseas marketing, and } \\
\text { Contact Centre }\end{array}$ & $\begin{array}{l}\text { Motor-claims } \\
\text { department, } \\
\text { Non-motor claims } \\
\text { department, and five } \\
\text { business units (Agent } \\
\text { business unit, Broker } \\
\text { business unit, Financial } \\
\text { business unit, } \\
\text { Commercial lines } \\
\text { business unit, and } \\
\text { Personal lines business } \\
\text { unit) }\end{array}$ \\
\hline
\end{tabular}

Table 1. Background information of the organisations

There were three criteria for choosing participating organisations. Firstly, organisations needed to have implemented CRM systems within the past three years and were currently using the systems. Secondly, organisations needed to be medium or large-sized businesses since organisations of these sizes are typical CRM users (Srivihok \& Batanov, 2005). The third criterion was that the selected organisations needed to be using the main CRM modules, such as customer service, sales automation, and marketing automation modules. Three 
organisations were selected as research sites: a hospital, an insurance company, and an innovative office automation solutions provider in Thailand. Having organisations from different industries allowed us to extend the findings to develop a rich understanding of postadoptive changes (Harris \& Sutton, 1986).

\subsection{Data collection}

Semi-structured interviews were the main data collection technique employed in this study. Participants were selected according to the likelihood that they could offer theoretical insight into changes associated with CRM implementation. All of the interview sessions were one-onone to obtain insightful information from participants' real experiences and perceptions. Each interview contained questions about participants' work experience and educational background, their experiences related to information technology, their perception toward CRM systems, their CRM use, and ensuing changes. There were three different sets of interview questions for three groups of participants - end-users, IT support staff, and management. The main reason to interview different groups of participants was to obtain rich information from the perspectives of the organisation, users, and IT staff. According to Alvesson (1995), data from both managerial and technical experts can help eliminate the possible managerial bias that can occur when only managers are included in research studies. We also used supporting documents such as IT system infrastructure documents, implementation plans, and user manuals to enrich our understanding and, in some cases, to verify participants' quotes. Participants were selected based on their experience of using the CRM system in their daily work routines and their ability to give us rich information relating to changes that occurred after CRM implementation. The total number of participants in this study was 43 (14 for RC, 11 for HP, and 18 for BI).

\subsection{Data analysis}

We adopted three concurrent data analysis processes (data reduction, data display, and conclusion drawing and verification) proposed by Miles and Huberman (1994) to analyse interview data. Within-case and cross-case analyses were conducted to investigate sociotechnical change in a specific organisation and to compare the organisation with other organisations to identify similarities and differences. In this study, the data reduction commenced with our choice of a socio-technical perspective to examine the change process. During the interview process, data reduction was achieved by making short notes. During the data analysis, the coding process began by labelling data with low-level codes. Next, we grouped conceptually related low-level codes into interpretive codes - interpretive codes are used to identify categories that coherently conceptualise the change process. In the last stage, the pattern codes were developed. The next step involved linking critical events to gaps as well as responses and outcomes to theorise socio-technical changes. The critical events, gaps, as well as responses and outcomes were derived from either low-level codes, interpretive codes, or pattern codes. To explain how socio-technical changes unravel, we traced the process from a critical event to gaps, as well as responses and outcomes.

\section{Findings}

In this section, socio-technical changes from CRM implementation are discussed for RC, HP, and BI. 


\subsection{RC}

The introduction of the CRM system can transform and readjust all components of the existing socio-technical system. The previous structure of work at RC focused on a decentralised structure by using basic office applications to manage customer data without the requirement to share them among sales professionals. The new CRM system ultimately changed the organisational structure, work processes, work systems, and individual work practices. The changes in the socio-technical components included actors (sales professionals and newly appointed CRM officers), tasks (input customer data and systematic task management), structure (centralised customer repository, integrated work processes, and new organisational rules), and technology (CRM and RIS system), which are explained below. The RIS system was used as an in-house system to maintain customer information and create invoices. The critical events, gaps between socio-technical components, as well as responses and outcomes are discussed to explain how the observed changes were unveiled (See Table 2).

Actor: RC established a new CRM team who were newly hired for the sole purpose of supporting CRM implementation. After the CRM implementation, sales professionals and CRM officers were required to work closely together. All customer accounts created by sales professionals were required to be approved and verified by the CRM team. The sales supervisor explained that, "Sales professionals must send a request to the CRM team to verify new accounts. It takes time to wait for approval from the CRM team. Previously, we were able to input customers' data without the need for verification." (RC14)

Task: The introduction of CRM added a new task for sales professionals to input customer data into the CRM system. In particular, they were required to switch from using systems of their choice (e.g., Excel and Google calendar) to using two organisational sanctioned systems (RIS and CRM systems) to complete their work tasks. As a result, their work processes now included using CRM as a centralised data repository to input customer data, produce sales forecasts, and create sales activities. Indeed, the task of inputting customer data into the CRM system had a significant impact on sales professionals' work practices. One participant stated that, "There is an additional work task. Users must input customers' data in the CRM system before generating orders in the RIS system." (RC07)

In addition, the interviews suggested that data were not well prepared because of the lack of appropriate data cleansing during migration (critical event). As a result, some data were not migrated into the new CRM system and some data were duplicated (gap). The critical event of a poor data migration strategy (including duplicated data and customer data loss which occurred during data migration) led to the generation of a gap in the technology-task components. To address this gap, the management introduced an additional task of manually inputting customer data into the system as well as requiring the sales professionals to work with the CRM team to remove duplicated accounts (incremental adaptation). Although the data problem was resolved, the sales professionals were left with the feeling that their professional identity had been challenged because they were asked to perform what they considered non-sales related tasks. A sales professional explained that, "During the period of data migration from the previous system to the CRM system, some data were lost. I need to put my own customers' accounts manually into the CRM system. I have hundreds of accounts to enter into the CRM system. On top of that, all accounts need to be approved by the CRM team. My task is to sell products not to perform administration tasks." (RC05) Therefore, this intervention can be simultaneously considered as a successful intervention to alleviate the gap between technology and task 
components and a failed intervention because it introduces a new misalignment between actor and task.

Structure: Following the introduction of CRM, information about which sales professionals worked with which customers became transparent and visible among all sales professionals. The increased transparency of sales and customer data contributed to the increasing conflict among the sales staff. Some sales professionals believed that others were stealing their customer accounts without informing them. To address this issue, the management set up new rules to resolve conflicts that occurred during the change process. The new rules were related to sales authority and the owners of accounts with several criteria to eliminate the conflicts among the sales staff. For example, the organisation set up a strict sales boundary. A boundary can be a geographical area or business types of customer organisations in which each sales team is able to sell products. In this case, the sales professionals were not allowed to sell products outside of their assigned boundaries. The CRM team was granted the authority to resolve conflicts related to sales boundaries. In particular, the CRM officers were empowered to decide whether a sales professional met the criteria to be the owner of a specific customer account.

Technology: The CRM system was integrated with the existing systems, including the RIS system. Sales professionals could use the CRM system to view customer information anytime, anywhere, without the need to carry printed copies of customer profiles as they did before the CRM implementation. Both sales professionals and the CRM team used the CRM system to generate reports.

\begin{tabular}{|c|c|c|c|}
\hline Critical events & $\begin{array}{l}\text { Gaps between } \\
\text { components }\end{array}$ & Response to gaps & Outcomes \\
\hline $\begin{array}{l}\text { Poor data migration } \\
\text { strategy } \\
\text { Identifying problems } \\
\text { with data quality } \\
\text { including duplicated } \\
\text { data and customer data } \\
\text { loss occurred during the } \\
\text { data migration stage. }\end{array}$ & $\begin{array}{l}\text { Technology-Task } \\
\text { Data was not well } \\
\text { prepared because of the } \\
\text { lack of appropriate data } \\
\text { cleansing and migration. } \\
\text { As a result, some data } \\
\text { was not migrated into } \\
\text { the new CRM system } \\
\text { and some data was } \\
\text { duplicated. }\end{array}$ & $\begin{array}{l}\text { Incremental adaptation } \\
\text { The management } \\
\text { introduced an additional } \\
\text { task of manually } \\
\text { inputting customer data } \\
\text { into the system, as well } \\
\text { as requiring the sales } \\
\text { professionals to work } \\
\text { with the CRM team to } \\
\text { remove duplicated } \\
\text { accounts. }\end{array}$ & $\begin{array}{l}\text { Due to this intervention, } \\
\text { the data problem or the } \\
\text { gap between technology } \\
\text { and task components } \\
\text { was resolved. However, } \\
\text { this response introduced } \\
\text { a new gap between actor } \\
\text { and task. }\end{array}$ \\
\hline $\begin{array}{l}\text { Increased transparency } \\
\text { After its implementation, } \\
\text { the CRM system became } \\
\text { a "transparency tool" } \\
\text { that revealed sales } \\
\text { activities among sales } \\
\text { professionals. }\end{array}$ & $\begin{array}{l}\text { Technology-Actor } \\
\text { The critical event of } \\
\text { increased transparency } \\
\text { negatively affected the } \\
\text { relationships among } \\
\text { sales professionals. Some } \\
\text { sales professionals } \\
\text { thought that others were } \\
\text { stealing their customer } \\
\text { accounts without } \\
\text { informing them. }\end{array}$ & $\begin{array}{l}\text { Punctuation } \\
\text { Increased transparency } \\
\text { led to conflict among } \\
\text { users. To address the } \\
\text { conflicts, management } \\
\text { set up new rules to } \\
\text { prevent cross-selling } \\
\text { across districts. }\end{array}$ & $\begin{array}{l}\text { The intervention not only } \\
\text { failed but also added a } \\
\text { new misalignment } \\
\text { between structure and } \\
\text { actor manifesting in the } \\
\text { distrust among sales } \\
\text { professionals. }\end{array}$ \\
\hline
\end{tabular}

Table 2. Summary of the critical events, gaps, responses and outcomes in the RC organisation 
After its implementation, the CRM system became a "transparency tool" that stopped ambiguity in sales activities among sales professionals. Information was shared within the Sales department and among sales teams with a different level of authorisation to view the data. In particular, the critical event of increasing transparency of customer data led to the generation of a gap in technology-actor components, which negatively affected the relationships among sales professionals (gap). One participant explained that, "There was a conflict among the sales staff. Users were able to search for customers' accounts in the CRM system. It showed details of account owners. Previously, this kind of data was not shared with others." (RC07) As a response, management set up new rules to prevent cross-selling across districts (punctuation), which led to distrust and unpleasant relationships among sales professionals. A sales professional explained that, "In the beginning, the CRM team got confused regarding how to manage conflicts in the Sales department. Management then set up new rules to solve those conflicts. Nowadays, the CRM team applies these rules with several criteria that consider account owners, business type and sales' district boundaries to all sales professionals." (RC12) In this case, the intervention not only failed but also added a new misalignment between structure and actor, manifesting in distrust among sales professionals.

Further examination of responses and outcomes from gaps showed that two critical events in the RC organisation led to the generation of different gaps in the socio-technical components. These gaps occurred between technology-task, and technology-actor components. As a result, these gaps and responses led to the generation of unintended consequences including additional tasks, loss of benefits, and conflict among users. Some issues were resolved, while others remained at the time of data collection.

\subsection{HP}

HP initially implemented CRM as a mandatory system in three departments: Local Marketing, Overseas Marketing, and the Contact Centre departments. Marketing officers used the CRM system to analyse customer data, create marketing campaigns, and segment customer groups. The main objective was to increase customer loyalty and the customer retention rate. The email correspondent team under the Overseas Marketing department used the CRM system to reply to e-mails from foreign customers using a pre-defined template. The system generated a serial number (SR number) to track and store the email correspondence. The CRM system completely replaced the previous email systems (Lotus Notes and Microsoft Outlook).

The Contact Centre department used the CRM system to record and view customers' data, such as names and telephone numbers. The CRM system was integrated with the Cisco IP phone to automatically recognise customers' names. For HP, the new CRM system ultimately changed the organisational structure, work processes, work systems, and individual practices. The changes in the socio-technical components included actors (staff and management committee team), tasks (customer-centric focused, systematically reply to customers' e-mails), structure (data integration, additional work process, and systematic workflow), and technology (CRM and hospital systems), which are explained below. The critical events, gaps between socio-technical components, as well as outcomes are discussed to explain how the changes were unveiled (See Table 3). It is important to note that HP did not introduce appropriate interventions to address the emerging gaps from critical events, which meant the misalignments between system components persisted.

Actor: The organisation set up a new management committee to brainstorm and generate the implementation plan. This team also provided support for all activities related to the CRM 
system and maintained the CRM system. A Local Marketing staff member explained that, "The organisation set up a management committee to support the CRM system. This committee was comprised of top management, middle management, and team leaders who had expertise with the CRM system. This team attempted to support CRM users if they made a request, such as implementing more features or modules, customising the system to suit users' work practices, and so on." (HP06)

Task: In the Local Marketing and Contact Centre departments, a customer-centric focus was adopted by focusing on providing personalised services to customers in order to increase customer retention and acquisition. The Local Marketing staff focused on increasing revenues, developing new products, creating campaigns, marketing activities, and maintaining relationships with customers to enhance customer satisfaction. However, the CRM system affected individuals' work performance due to an increase in abandoned calls in the Contact Centre department.

The new requirement for the Contact Centre staff to input customers' information into the CRM system could be considered as a critical event which led to the development of a gap between task-structure components. This is because there was inadequate staff in the Contact Centre to manage the workload (gap). Previously, Contact Centre staff used only the TrakCare system. After CRM was introduced, they were required to use both systems. They needed to input data into the TrakCare system as well as the CRM system. It took a minute to one and a half minutes to complete data entries in both systems. To cope with the increased data entry demand, some users did not complete all data entries. During the interview period, there was no further information on whether this problem had been resolved or not. The head of the Contact Centre department explained that, "The CRM system affects KPIs, increases talk time, and increases abandoned calls. Therefore, we avoid some tasks such as inputting customer data into the system." (HP10)

Structure: Data integration was introduced in the Local Marketing department. The CRM system became an additional work system used to analyse customer information and create systematic campaigns. Work processes were changed to incorporate CRM as a centralised database. For example, Contact Centre staff needed to first access the CRM system prior to other systems. Work routines were changed by adding tasks that users needed to perform on the CRM system. For example, front office staff needed to check customer preferences in the CRM system to serve customers' needs.

The Overseas Marketing department used the CRM system to respond to customers' inquiries by using a pre-defined response template and generating a serial number (SR number) to manage email correspondence. Previously, they used Microsoft Outlook to reply to e-mails and manually tracked records of incoming e-mails. In this case, the new communication tool that the Overseas Marketing department were required to use is a critical event. The team had previously used the Outlook application, which was now superseded by the CRM system, leading to the development of a gap between structure-task components. Users had to spend additional time to create SR numbers and input data (gap). As a result, this event had a negative effect on KPIs in terms of decreasing numbers of response e-mails to customers. In other words, the new CRM system completely changed the email correspondence team's work practices. One of the Overseas Marketing staff explained that, "Prior to the CRM system, we sent approximate 40 response e-mails to customers a day. After CRM replaced Microsoft Outlook, it increased our workload because additional work steps were needed in the CRM system such as creating e-mail templates and generating serial numbers. The number of e-mail replies was now halved." (HP04). 
The Contact Centre department used the CRM system as the primary system to identify and recognise customers when they call the hospital. The introduction of the CRM system created additional tasks in terms of inputting and updating customer information. The head of the Contact Centre department described that, "Previously, I used only the TrakCare system. After CRM was introduced, I must use both systems. I must input data into the TrakCare system and then, I must also input data into the CRM system as well. It affects my work performance. It takes a minute to one and a half minutes to complete all these." (HP10)

Technology: In the Local Marketing department, the CRM business intelligence tool was used to gather, store, analyse, and access customer data. Users were able to access customers' database without the need to ask for data from the IT department. In the Overseas Marketing department, the CRM system completely replaced the previous systems used to support customer enquiry (Lotus Notes and Microsoft Outlook). In the Contact Centre department, the staff admitted that it was more convenient to use the CRM system to find information rather than using several systems as before.

\begin{tabular}{|c|c|c|c|}
\hline Critical events & $\begin{array}{l}\text { Gaps between } \\
\text { components }\end{array}$ & $\begin{array}{l}\text { Response } \\
\text { to gaps }\end{array}$ & Outcomes \\
\hline $\begin{array}{l}\text { Requirement to input } \\
\text { customer information } \\
\text { Contact Centre officers } \\
\text { were required to input } \\
\text { customer data into the } \\
\text { CRM system. }\end{array}$ & $\begin{array}{l}\text { Task-Structure } \\
\text { The existing number of } \\
\text { Contact Centre staff was } \\
\text { inadequate to support the } \\
\text { task at the initial stage of } \\
\text { post-adoption. }\end{array}$ & $N / A$ & $\begin{array}{l}\text { Some users minimally used some } \\
\text { features to finish work on time. Since } \\
\text { the organisation did not attempt to } \\
\text { mitigate the problem, the gap between } \\
\text { task and structure persisted. }\end{array}$ \\
\hline $\begin{array}{l}\text { Replacement of new } \\
\text { communication tool } \\
\text { The e-mail } \\
\text { correspondence team had } \\
\text { previously used the } \\
\text { Outlook application, } \\
\text { which was now } \\
\text { superseded by the CRM } \\
\text { system. }\end{array}$ & $\begin{array}{l}\text { Structure-Task } \\
\text { The existing workflow } \\
\text { was affected, and the } \\
\text { work tasks were added. } \\
\text { After CRM } \\
\text { implementation, users } \\
\text { had to spend additional } \\
\text { time to create SR } \\
\text { numbers and input data. }\end{array}$ & $N / A$ & $\begin{array}{l}\text { This event led to a negative effect on } \\
\text { KPIs in terms of decreasing the } \\
\text { numbers of response e-mails to } \\
\text { customers. Since the organisation did } \\
\text { not attempt to mitigate the problem, } \\
\text { the gap between structure and task } \\
\text { persisted. }\end{array}$ \\
\hline $\begin{array}{l}\text { Slow connection to CRM } \\
\text { server } \\
\text { The location of the CRM } \\
\text { system server slowed } \\
\text { down access to the } \\
\text { database. Furthermore, } \\
\text { the CRM server and the } \\
\text { Hospital Information } \\
\text { System (HIS) server were } \\
\text { not located in the same } \\
\text { place. }\end{array}$ & $\begin{array}{l}\text { Technology-Task } \\
\text { It led to a slow CRM } \\
\text { server response. In } \\
\text { addition, it took longer to } \\
\text { synchronise data between } \\
\text { the HIS system and the } \\
\text { CRM system. The data } \\
\text { was updated daily, not in } \\
\text { real-time. }\end{array}$ & $N / A$ & $\begin{array}{l}\text { This event affected work performance } \\
\text { in terms of increased time needed to } \\
\text { finish tasks. Since the organisation did } \\
\text { not attempt to mitigate the problem, } \\
\text { the gap between technology and task } \\
\text { persisted. }\end{array}$ \\
\hline
\end{tabular}

Table 3. Summary of the critical events, gaps, responses and outcomes in the HP organisation

However, users experienced some problems in their use of the CRM system. The CRM system server was physically located far away from the users. The physical distance of the CRM system server in particular could be considered as a critical event, which led to the generation of a gap between technology-task components and the slow CRM server response (gap). This 
event led to negative impacts on work performance in terms of increased time needed to finish tasks. The executive office manager explained that, "The CRM system server is located in Bangkok. We need to access the server via a WAN link. Access via the CRM system involves delay for a while. In addition, the hospital's in-house system is located here. Therefore, the data from the HIS system and the CRM system are not real-time data. The data is updated daily. It affects our work performance because of speed. We must respond to customers' e-mails as soon as possible. Using the CRM system instead of Microsoft Outlook, sometimes leaves us hanging around. It wastes our time." (HP04)

Further examination of the outcomes of gaps showed that three critical events in the HP organisation led to the generation of different gaps between task-structure and technologytask components. As a result, these gaps led to the generation of unintended consequences including increased abandoned calls, a negative effect on KPIs, and a negative effect on work performance.

\section{$4.3 \mathrm{BI}$}

Similar to RC and HP, BI introduced the CRM system as a mandatory system. BI implemented the CRM system in two departments - the Motor Claims department and the Non-Motor Claims department - as well as five business units (Agent business unit, Broker business unit, Financial business unit, Commercial Lines business unit, and Personal Lines business unit). The structure of the BI organisation was complicated in that it had both departments and business units. Therefore, the analysis of organisational change was conducted on a similar module used in different departments or business units. There were primarily two different work practices - that of the Contact Centre and that of the account executive (AE) and underwriter staff.

The BI organisation had contact centres in three business units: the Motor Claims contact centre, the Non-Motor Claims contact centre, and the Personal Line business unit. All three contact centre units used the Phone Call and Case Management module. The AE and underwriter staff used the Phone Call and Case Management module, the Visit Plan module, and the Renewal module. For BI, the new CRM system ultimately changed the organisational structure, work processes, work systems, and individual practices. The changes in the sociotechnical components included actors (staff and IT support team), tasks (systematic tasks, record customer information), structure (customer-centric data-focused, centralise customers' information, additional work process), and technology (CRM and in-house systems), which are explained below. The critical events, gaps between socio-technical components, as well as responses and outcomes are discussed to explain how the changes were unveiled (See Table 4).

Actor: Users were able to download reports from the CRM system without the need to request them from the IT department as before. The work system in the Contact Centre department was, therefore, more efficient and more systematic. Similarly, the AE and underwriter staff were able to obtain renewal data from the CRM system rather than asking for information from the IT department. A user explained that, "The CRM system assists in displaying all insurance policies that are going to expire." (BI03)

However, there were issues in terms of CRM usage. Inadequate training and the complexity of the CRM system could be considered as a critical event which led to the development of a gap between actor-task components. Users did not know how to use some features, which had a negative effect on work performance because they struggled to use CRM features to complete work tasks. A user explained that, "The work process in the CRM system was complicated. 
Additionally, training was inadequate. Furthermore, IT support staff were inadequate as well. At the initial stage of CRM usage, users faced issues such as not being fluent in using the system. As a result, the work processes were stopped and it was not possible to move to the next processes." (BI03) The organisation initiated training sessions and one-on-one support from the IT department, which can be considered as an incremental adaptation response to successfully alleviate this gap.

Task: After the CRM system was introduced, customer data was recorded into the CRM system in the Contact Centre department. Contact Centre officers used Case Management in the CRM system to assign tasks to responsible persons. Every transaction was recorded into the system. The AE and underwriter staff used the CRM system to replace the paper-based Visit Plans, to systematically assign Case Management, and to replace the manual work of renewing insurance policies. Another participant explained the process involved in completing her work tasks: "My task involves sending a renewal notice to the individual customer, not passing through a broker. I use the renewal report in the CRM system as a control sheet to remind me. Normally, the list of insurance policies that are going to expire shortly is transferred to the CRM system. I use this list to send an e-mail to customers. I can also check the status in the system." (BI03)

However, a management staff member mentioned that the CRM system had affected users' work performance regarding the amount of time needed to record customer information. In particular, the new requirement to input customer information into the system could be considered as a critical event, which generated a gap between task-structure components. A number of staff were unable to complete their tasks at the initial stage of post-adoption, which led to an increase in abandoned calls and a negative impact on work performance. The IT department attempted to streamline the user interaction with CRM and substantially reduce the working time (incremental adaptation). Due to this intervention, both parties were happy with the solution and the gap was successfully addressed. The team leader of the Motor Claims department explained that, "At the initial post-adoption stage of the CRM system, it had a huge effect on our work performance. It increased call time by one minute per call. If I received 60 calls, I would waste an hour per day. I raised the issue with the IT department that it was wasting our human resources and we needed to finish calls earlier. The IT staff came up with the solution of finishing the task within 30 seconds by removing unnecessary steps." (BI18)

Another critical event was that the different implementation periods of the Phone Call and Case Management modules across business units generated a gap between task-actor components. Some users were unaware that they had to use the Phone Call and Case Management modules in the CRM system, which led to conflict among users. Once users were made aware of the need to use the new CRM system (incremental adaptation), then the problem was resolved. A user explained that, "Conflict occurred among users across business units. It was a communication conflict. For example, the conflict occurred because of using the Phone Call and Case Management module. Some users were unaware that they had to use Case Management to send/receive cases from other business units. Once the CRM system had been completely implemented to all business units, then there were no conflicts." (BI10)

Structure: In the Contact Centre department, users could use the CRM system to view information related to a customer's account, such as the list of all insurance policies belonging to that customer. The organisation changed from a product-centric data focus to a customercentric data focus to align with their business strategy. Additionally, the information in the CRM system was integrated with the BKI application. Before CRM was introduced, BI had 
two existing systems in use called BKI app and e-Surveyor app. BKI app was mainly used for generating insurance policies and maintaining customer information. Users were able to click the icon in the CRM system to view further information about each insurance policy in the BKI application. Therefore, customer information became centralised, and the workflow was substantially changed after CRM implementation.

However, there was a critical event regarding the incomplete integration of CRM and the existing systems during the initial stage of implementation. This generated a gap between structure-task components. The provided structure of work did not support users to complete their tasks, which led to time-wasting in terms of staff double keying information to complete their work tasks. A management staff member explained that "At the initial stage of CRM adoption, information in the CRM system did not integrate with information in the e-Surveyor application. When I keyed information into the CRM system, the information was not displayed in the e-Surveyor application. We informed IT support staff that we would not do double work." (BI15) To address this gap, the IT team was instructed to fully integrate the two systems in the later stage of implementation (incremental adaptation), which successfully removed the misalignment between structure and task.

Technology: In the Contact Centre, the CRM system helped to identify customers through its integration with the phone system and other in-house systems. For the AE and underwriter staff, tools to support their work tasks were changed after the introduction of the CRM system. The CRM system was integrated with the existing in-house systems (mainly the BKI application). As a result, $\mathrm{AE}$ and underwriter staff were required to use the CRM system to systematically record customer data and inquiries. They used the CRM system to replace paper-based Visit Plans and the renewal of insurance policies. A management staff member confirmed that, "We have additional work. We shifted from manual work to work on the system. We need to record everything into the CRM system." (BI12)

However, the CRM system affected individuals' work practices because of the limitations of customisation and limited user experience with off-the-shelf software. In particular, the critical event of the workflow adjustment limitations generated a gap between technology-structure components. This affected the structure of work because the CRM system did not fit well with the existing workflow. This event led to a negative impact on work performance because users had to spend more time to learn and adapt to the new system. A user from the Agent business unit explained that, "The CRM system has several features. I feel that it is suitable for a marketing company or suitable for a business unit which takes care of retail customers. In my business unit, we take care of sales agents. It is unsuitable for the nature of our work." (BI02) The IT team attempted to customise the CRM system to suit the existing workflow (incremental adaptation). Due to this intervention, the problem was successfully resolved. A user explained that, "The CRM system is difficult to use and unsuitable for users. IT staff attempted to customise it to suit each business unit. From my point of view as a user, each business unit has different work processes." (BI02)

Also, this critical event generated a gap between technology-actor components. Most users were not familiar with the off-the-shelf software (gap), which had a negative effect on users' work routines. One of the participants explained that, "The wording in the CRM system and the wording that we use every day are totally opposite - for example, the words 'lead' and 'customer account'. We are not familiar with sales and marketing vocabulary. On top of that, the wording in the CRM system is in English." (BI08) The IT team provided extra support to users to help them 
adapt to the new system, including one-on-one and on the job training (incremental adaptation). Due to this intervention, the problem was successfully resolved.

Further examination of outcomes from gaps showed that five critical events in the BI organisation led to the generation of different gaps between technology-structure, technologyactor, structure-task, and task-actor components. As a result, these gaps led to the generation of unintended consequences including effect on work performance, additional work, conflict among users, struggles with workflow, and increased abandoned calls.

\begin{tabular}{|c|c|c|c|}
\hline Critical events & $\begin{array}{l}\text { Gaps between } \\
\text { components }\end{array}$ & Response to gaps & Outcomes \\
\hline $\begin{array}{l}\text { Customisation } \\
\text { limitations and } \\
\text { mismatch of the } \\
\text { terminology in the } \\
\text { CRM system } \\
\text { Customisation of the } \\
\text { CRM system had } \\
\text { limitations in terms of } \\
\text { workflow adjustment } \\
\text { and too many } \\
\text { unnecessary features. } \\
\text { Furthermore, users } \\
\text { were unfamiliar with } \\
\text { the terminology in the } \\
\text { CRM system. }\end{array}$ & $\begin{array}{l}\text { Technology-Structure } \\
\text { The CRM system did not } \\
\text { fit well with the existing } \\
\text { workflow. } \\
\text { Technology-Actor } \\
\text { The terminology in the } \\
\text { CRM system affected } \\
\text { users' work routines and } \\
\text { work practices. Most } \\
\text { users were not familiar } \\
\text { with the off-the-shelf } \\
\text { software. }\end{array}$ & $\begin{array}{l}\text { Incremental adaptation } \\
\text { The IT team attempted to } \\
\text { customise the CRM } \\
\text { system to suit the existing } \\
\text { workflow, as well as } \\
\text { supported users to adapt } \\
\text { to new system. }\end{array}$ & $\begin{array}{l}\text { Due to this intervention, } \\
\text { the effect on work } \\
\text { performance in terms of } \\
\text { spending more time to } \\
\text { learn and adapt to the } \\
\text { new system was } \\
\text { successfully resolved. }\end{array}$ \\
\hline $\begin{array}{l}\text { Incomplete integration } \\
\text { There was incomplete } \\
\text { integration of the two } \\
\text { systems at the initial } \\
\text { stage of } \\
\text { implementation. Users } \\
\text { had to input data twice } \\
\text { into both systems. }\end{array}$ & $\begin{array}{l}\text { Structure-Task } \\
\text { The provided structure of } \\
\text { work did not support } \\
\text { users to complete their } \\
\text { tasks. }\end{array}$ & $\begin{array}{l}\text { Incremental adaptation } \\
\text { This event led to } \\
\text { additional work in terms } \\
\text { of double keying } \\
\text { information to complete } \\
\text { the work processes. To } \\
\text { address this gap, the IT } \\
\text { team resolved the } \\
\text { problem by fully } \\
\text { integrating the two } \\
\text { systems. }\end{array}$ & $\begin{array}{l}\text { Due to this intervention, } \\
\text { the IT team was } \\
\text { instructed to fully } \\
\text { integrate the two systems } \\
\text { in the later stage of } \\
\text { implementation, which } \\
\text { successfully removed the } \\
\text { misalignment between } \\
\text { structure and task. }\end{array}$ \\
\hline $\begin{array}{l}\text { Different implement- } \\
\text { ation periods } \\
\text { Different } \\
\text { implementation } \\
\text { periods of the Phone } \\
\text { Call and Case } \\
\text { Management modules } \\
\text { in different business } \\
\text { units. }\end{array}$ & $\begin{array}{l}\text { Task-Actor } \\
\text { Some users were unaware } \\
\text { that they had to use the } \\
\text { Phone Call and Case } \\
\text { Management modules in } \\
\text { the CRM system. Each } \\
\text { department started using } \\
\text { the CRM system at a } \\
\text { different time. }\end{array}$ & $\begin{array}{l}\text { Incremental adaptation } \\
\text { This event happened } \\
\text { during the initial stage of } \\
\text { post- adoption. It led to } \\
\text { conflict among users. } \\
\text { Once users were made } \\
\text { aware of the need to use } \\
\text { the new CRM system, the } \\
\text { problem was resolved. }\end{array}$ & $\begin{array}{l}\text { Due to this intervention, } \\
\text { once users were made } \\
\text { aware of the need to use } \\
\text { the new CRM system, } \\
\text { then the conflicts among } \\
\text { users were resolved. }\end{array}$ \\
\hline $\begin{array}{l}\text { Inadequate training } \\
\text { and the complexity of } \\
\text { the CRM system } \\
\text { Users were not fluent at } \\
\text { using the CRM system } \\
\text { because of inadequate }\end{array}$ & $\begin{array}{l}\text { Actor-Task } \\
\text { Users did not know how } \\
\text { to use some features. }\end{array}$ & $\begin{array}{l}\text { Incremental adaptation } \\
\text { This event happened } \\
\text { during the initial stage of } \\
\text { post- adoption. It led to } \\
\text { struggles with workflow } \\
\text { because staff were unable }\end{array}$ & $\begin{array}{l}\text { Due to intervention, the } \\
\text { problem was successfully } \\
\text { resolved. }\end{array}$ \\
\hline
\end{tabular}




\begin{tabular}{|c|c|c|c|}
\hline Critical events & $\begin{array}{l}\text { Gaps between } \\
\text { components }\end{array}$ & Response to gaps & Outcomes \\
\hline $\begin{array}{l}\text { training and the } \\
\text { complexity of the CRM } \\
\text { system. }\end{array}$ & & $\begin{array}{l}\text { to move to the next } \\
\text { processes to accomplish } \\
\text { work tasks on time. To } \\
\text { address this } \\
\text { misalignment, the IT } \\
\text { support offered } \\
\text { additional training } \\
\text { sessions and one-on-one } \\
\text { support. }\end{array}$ & \\
\hline $\begin{array}{l}\text { Requirement to input } \\
\text { customer information } \\
\text { Users were required to } \\
\text { input customer data } \\
\text { into the CRM system. }\end{array}$ & $\begin{array}{l}\text { Task-Structure } \\
\text { A number of staff were } \\
\text { unable to complete their } \\
\text { tasks at the initial stage of } \\
\text { post-adoption because of } \\
\text { the workload, human } \\
\text { resource limitations, time } \\
\text { limitations, and system } \\
\text { interruption. }\end{array}$ & $\begin{array}{l}\text { Incremental adaptation } \\
\text { This event led to } \\
\text { increased abandoned calls } \\
\text { and had a negative effect } \\
\text { on work performance. } \\
\text { The IT department came } \\
\text { up with a solution to } \\
\text { reduce work processes in } \\
\text { the CRM system. }\end{array}$ & $\begin{array}{l}\text { Due to this intervention, } \\
\text { users and the IT team } \\
\text { were happy with the } \\
\text { solution. }\end{array}$ \\
\hline
\end{tabular}

Table 4. Summary of the critical events, gaps, responses and outcomes in the BI organisation

\subsection{Cross-case analysis}

This section discusses the critical events and gaps that reveal misalignment among the four socio-technical components as well as responses, if any, and outcomes (see Figure 1). Taken together, the generation of gaps had significant impacts on individuals in terms of (i) the relationship among users and (ii) work practices, as well as organisations in terms of (iii) organisational performance.

\subsubsection{Relationship among users}

The generation of gaps between technology-actor and task-actor components in the RC and BI cases led to unintended behavioural change in actors due to benefit losses and conflicts among users. In particular, the rollout and nature of CRM use affected the socio-technical systems in different ways. In the BI case, each department started using the CRM system at different times. The different implementation periods led to a misunderstanding among users. The conflict occurred because some users were unaware that they had to use the Case Management feature in the CRM system to send/receive cases to/from other business units. Once users were made aware of the need to use the new CRM system (incremental adaptation), then the problem was resolved. In the RC case, after the implementation, the CRM system became a transparency tool because sales professionals' sales activities were no longer private information to each sales staff. As a result, the increased transparency of sales and customer information negatively affected the relationships among sales professionals. This led the system into a new deep structure whereby sales professionals could only sell products within their sales boundary due to the visibility of sales data in the CRM system.

\subsubsection{Work practices}

Users from all three organisations were required to change their work practices to adapt to new CRM system implementations. However, the gaps between the socio-technical components produced several negative impacts on work practices and work performance 
albeit temporarily in some cases. In the BI case, the gap of actor-task components due to inadequate training and the complexity of the CRM system led to delay in accomplishing work tasks. The organisation initiated training sessions and one-on-one support from the IT department, which can be considered as an incremental adaptation response to successfully alleviate this gap. In the RC case, the gap between technology-task components from a poor data migration strategy resulted in the addition of an unnecessary task for users to manually input customer data into the system to remove duplicated accounts (incremental adaptation). Although the data problem was resolved, the sales professionals were left with the feeling that their professional identity had been challenged because they were asked to perform what they considered non-sales related tasks.

In the HP case, the gap between technology-task components as a result of a slow connection to the CRM server led to more time required to finish tasks. Since the organisation did not attempt to mitigate the problem, the gap between technology and task persisted. In addition, in the BI case, the gap between technology-structure and technology-actor components, based mainly on the customisation of the CRM system and the different terminologies used in the CRM system, led to individuals temporarily spending more time learning and adapting to the new system. The IT team attempted to customise the CRM system to suit the existing workflow (incremental adaptation). Due to this intervention, the problem was successfully resolved.

Lastly, the gap between task-structure components in the HP and BI cases led to increased abandoned calls in both cases. The team in the HP case had previously used the Outlook application, which was now superseded by the CRM system, leading to the development of a gap between structure and task components and a negative effect on work performance in terms of the number of response e-mails to customers (KPIs). Since the organisation did not attempt to mitigate the problem, the gap between structure and task persisted. In the BI case, the task-structure gap was the result of the incomplete integration of CRM systems with the existing system at the initial stage of implementation, leading to time wasting because staff had to enter the same information into both systems to complete their work tasks. To address this gap, the IT team was instructed to fully integrate the two systems in the later stage of implementation (incremental adaptation), which successfully removed the misalignment between structure and task.

\subsubsection{Organisational performance}

In terms of consequences on organisational performance, all three organisations changed the structure of work, reshaped their work processes and work systems in order to integrate the new ES with their existing systems, and set up appropriate organisational policies to support the use of the CRM system. However, these changes had negative effects on organisational performance. In the BI case, the gap between actor-task components due to inadequate training and the complexity of the CRM system temporarily affected organisational performance negatively at the initial stage of CRM implementation because users were struggling with some processes and unable to move to the next processes to accomplish work tasks.

Similarly, the gap between technology-task and technology-actor components in the three cases led to increased time needed to finish tasks. As a result, the overall organisational performance was affected, in some cases temporarily and others permanently. In the RC case, the data migration issue led to the creation of a gap between sales professionals' tasks and 
CRM technology. Sales professionals had to manually input data into the system, which is considered as an incremental adaptation.

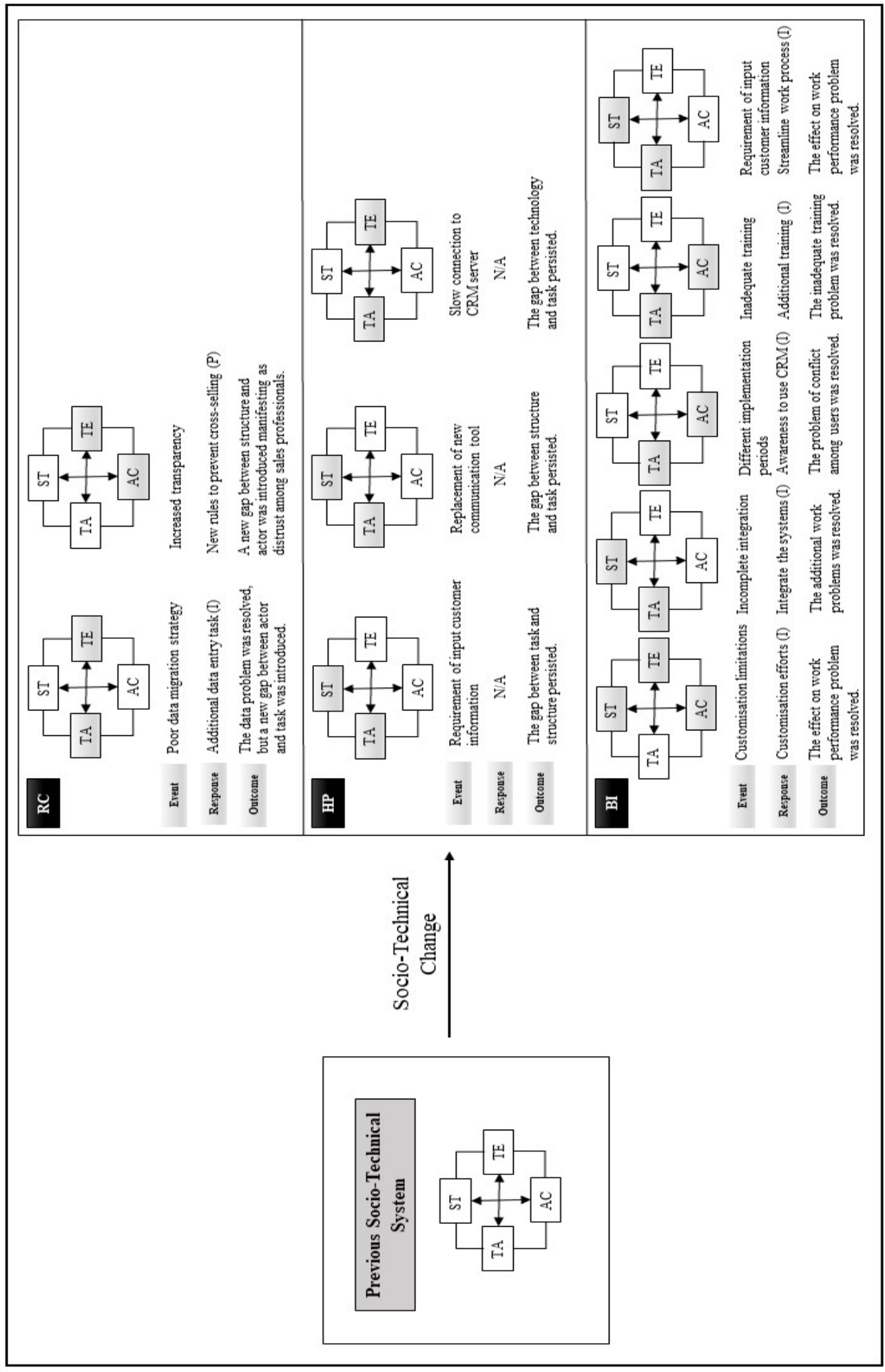

Figure 12: The critical events, gaps, responses, and outcomes from the three organisations

2 Note that ST, TA, TE, AC are the abbreviations for structure, task, technology and actor, respectively.

The notation of (I) stands for incremental adaptation and (P) stands for punctuation. 
This gap also impacted on organisational performance in terms of meeting the sales targets. In the HP case, the synchronisation of data between the CRM system and the HIS system did not occur in real time, which subsequently delayed the work process and negatively impacted organisational performance. Since the organisation did not attempt to mitigate the problem, the problem remained. In the BI case, the critical event of customisation limitations, including workflow adjustment limitations and users' unfamiliarity with the terminology in the CRM system, had a negative but temporary impact on the structure of work and users' work routines because the CRM system did not fit well with the existing workflow.

Lastly, the gap between task-structure components in the HP and BI cases led to increased abandoned calls and negatively affected users' KPIs. Since users had to spend time to input customer information, abandoned calls from customers increased. This permanently and negatively impacted organisational performance in the HP case as the organisation did not attempt to mitigate the problem. A similar problem temporarily impacted organisational performance in the BI case. Both the users and the IT team were happy with the solution. In conclusion, the findings across the three cases show that CRM implementations affected organisational performance, as well as individual work practices and relationships among users.

\section{Discussion and Conclusion}

\subsection{Discussion}

This research applied a PSIC model as a framework to explain the change process through critical events, gaps between socio-technical components (actor, task, structure, and technology), as well as responses and outcomes in the post-adoption of ES implementation. The results revealed that the new ES became a centralised database, changed the way customer data was viewed, changed the pattern of communication among users, became a control mechanism between management and users, and changed their structure of work. This led to the generation of gaps in socio-technical components and produced consequences, some of which were unintended.

The findings deepen our understanding of the change process by tracing critical events that generate gaps in the socio-technical components, responses and outcomes manifested in changes in organisational performance, the social system, and individual practices. Lyytinen and Newman (2008) argue that outcomes ranging from a failed intervention to a crisis that adds new misalignments into a system are likely to be generated from an event or a response. Our results complement those of Lyytinen and Newman (2008), in that there were two types of responses - incremental adaptation and punctuation - in the three organisations. These responses to address gaps led to the generation of outcomes.

In terms of the change outcomes, the findings revealed that CRM system implementation can lead to conflict among users with a negative effect on work performance. The analysis across two cases (RC and $\mathrm{BI}$ ) revealed that the misalignment between technology-actor and task-actor components led to unintended conflict among users. In addition, the findings across the three cases revealed that the introduction of the CRM system led to a mismatch between the CRM system and work practices in some departments. The misalignment between task-actor, tasktechnology, task-structure, technology-structure, and technology-actor components had a negative effect on work performance. When CRM was introduced into these organisations, it was perceived as an additional work system for employees in some departments across the 
three cases. For example, users were required to log in to the CRM system to input customer information or record customers' requests or inquiries. Users were required to use the CRM system first before working with other systems to complete their tasks. The findings also explained that all three organisations changed their structure of work and set up appropriate organisational policies to support the use of the CRM system after its implementation. These changes led to negative effects on organisational performance, which is far from the ideal objectives that these organisations aimed for.

Our results complement those by Bloomrosen et al. (2011), MacKay and Chia (2013), and Strong and Volkoff (2010), who argue that workflow adjustment as a result of CRM system implementations can impact work performance and effectiveness. Our results also confirm earlier studies regarding conflict among users. For example, in studies by Newell et al. (2002) and Rollins (2012), unfavourable changes in communication patterns and practices and negative impacts on social relationships were found to be unintended consequences associated with complexities of software use. In terms of effect on work performance, our results complement studies by Ignatiadis and Nandhakumar (2007) and Williams and Hardy (2005), which argue that unintended consequences in work performance are a result of changes in work practices associated with new system implementations.

This study extends the extant literature on enterprise systems and organisational change by explaining the sequence of change associated with ES implementations. Prior studies have paid little attention to all the impacts of changes on organisational structures and policies, work processes, individual practices, and relationships among employees. Some IS studies have independently shed light on the area of individual practices, work practices, adaptation behaviours, and job outcomes relating to IS implementation (Bala \& Venkatesh, 2015; Kim et al., 2012; Lyytinen \& Newman, 2008; Lyytinen et al., 2009; McLeod \& Doolin, 2012). For instance, Bala and Venkatesh's (2015) study focused on individual adaptation to IT and job outcomes.

Some IS studies have applied the notion of institutional logics to study organisational change associated with new information systems (Lyytinen et al., 2009; Yoo et al., 2007; Soh \& Sia, 2004). For instance, Soh and Sia (2004) suggest that organisations can address misalignment by package customisation or organisation adaptation, which include the redesign of organisational processes and structures. Similarly, this study found that system or workflow customisation to suit users' work practices can reduce misalignment between users (actor) and new ES implementation (technology). Despite the above, prior studies have not offered indepth explanations of how ES implementation affects changes at the organisational and individual levels. This study addresses this gap by providing a theoretical understanding of how ES implementation affects organisational structure and individual work practices in the post-adoption of CRM implementation. The findings can help organisations to be aware of unintended consequences associated with enterprise implementation that may occur after CRM implementation.

Although several studies have investigated CRM adoption and implementation at an organisational level (Awasthi \& Sangle, 2012; Chuchuen \& Chanvarasuth, 2011; Hung et al., 2010; Ko et al., 2008), they have focused on post-adoption changes in terms of CRM use and organisational performance (Sebjan et al., 2014). Klein and Kozlowski (2000) suggest that there is a lack of multi-level studies that can provide a rich understanding of phenomena that unfold across levels in an organisation. This study adds new knowledge to the current enterprise 
system research in the context of the CRM system by developing an understanding of both individual work practices and organisational change in the post-adoption stage of ES implementation. For instance, the findings showed that in BI, the critical event of the new requirement to input customer information into the system generated a gap between taskstructure components. A number of staff were unable to complete their tasks at the initial stage of post-adoption (gap), which led to an increase in abandoned calls and a negative impact on work performance (outcome). The result showed that changes at the individual and organisational levels were interrelated and need to be considered in theorising change following IS implementation.

\subsection{Conclusion}

\subsubsection{Theoretical and practical contributions}

In terms of the theoretical contribution, this study used a socio-technical perspective as a lens to study the socio-technical changes related to ES implementation. The findings revealed that all four interacting socio-technical components experienced changes after the introduction of an ES in an organisation. Additionally, the sequence of change proposed by Lyytinen and Newman's (2008) study enabled this study to identify gaps or misalignments that occurred during the ES implementation process. The mutually changing components could be examined, while identifying critical events and gaps. The critical events, which occurred during the change process, led to the generation of gaps between components. These gaps led to responses in some organisations and change outcomes that occurred in the post-adoption stage of CRM implementation. This study provides a richer vocabulary for a process of change by revealing consequences relating to the generation of gaps between the socio-technical components.

In terms of practical contributions, the findings offer strong evidence that organisations should take a proactive approach by preparing appropriate resources and support for successful ES implementation. In particular, organisations should be aware of unanticipated events and unintended outcomes that may occur during the change process. Since these events, as well as responses and outcomes, cannot be predicted in advance, they may require spontaneous interventions as they arise to increase user acceptance and to realise the benefits from ES implementation.

\subsubsection{Limitations of the study}

The study also has limitations that should be acknowledged. Firstly, at the time of the interview sessions, participants had been going through the change process relating to the CRM system for at least one year or more. It is not possible to perfectly capture every moment of the change process because the change process is both complex and long. The retrospective nature of this research may affect the way participants recalled their entire change process. To minimise the retrospective nature of the study, we asked additional questions to allow participants to recall circumstances in the past and to elaborate and confirm their answers (Huber \& Power, 1985). Secondly, research findings generated in qualitative research are difficult to generalise because the findings are strongly impacted by individuals' perspectives and values (Lewis \& Ritchie, 2003). To enhance the generalisability of the findings of this study, multiple cases and cross-case analysis were employed to assess similarities and differences in results across three cases and to strengthen the findings. 


\subsubsection{Future research}

An aspect that needs further examination relates to the outcomes of ES usage. Even though the results of this study represent the outcomes of using an ES, the study did not investigate how an ES shapes organisational performance. There is a need for further research on how organisations can improve their performance associated with ES implementation. This study focused on different organisational contexts from three different types of business to reveal similarities and differences regarding organisational change after CRM implementation, rather than focusing on national and organisational cultural contexts.

Future research could expand this study to consider the influence of culture on organisational change. This study was conducted in Thailand, and it is suggested that the study be replicated in different countries in order to investigate other cultures. Future research could expand this study to examine the cross-country context in order to deepen the understanding of different cultural backgrounds. Finally, this research studied ES implementation in the context of the CRM system. Future research could use this study and apply it to other ES contexts to examine the change process in the post-adoption stage.

\section{References}

Aburub, F. (2015). Impact of ERP systems usage on organizational agility. Information Technology \& People, 28(3), 570-588. doi:10.1108/ITP-06-2014-0124

Alvesson, M. (1995). Management of knowledge-intensive companies. New York, NJ: Walter de Gruyter

Awasthi, P., \& Sangle, S. P. (2012). Adoption of CRM technology in multichannel environment: A review (2006-2010). Business Process Management Journal, 18(3), 445-471. doi:10.1108/14637151211232641

Bala, H., \& Venkatesh, V. (2015). Adaptation to information technology: A holistic nomological network from implementation to job outcomes. Management Science, 62(1), 156-179. doi:10.1287/mnsc.2014.2111

Bloomrosen, M., Starren, J., Lorenzi, N. M., Ash, J. S., Patel, V. L., \& Shortliffe, E. H. (2011). Anticipating and addressing the unintended consequences of health IT and policy: a report from the AMIA 2009 Health Policy Meeting. Journal of the American Medical Informatics Association, 18(1), 82-90. doi:10.1136/jamia.2010.007567

Chuchuen, C., \& Chanvarasuth, P. (2011). The adoption factors of e-CRM in service sector of thai SMEs. Presented at the International Conference on Networking and Information Technology, Wuhan, China

Davis, F. D. (1993). User acceptance of information technology: System characteristics, user perceptions and behavioral impacts. International journal of Man-Machine Studies, 38(3), 475-487. doi:10.1006/imms.1993.1022

Dong, S. (2012). Decision execution mechanisms of IT governance: The CRM case. International Journal of Information Management, 32(2), 147-157. doi:10.1016/j.ijinfomgt.2011.09.003

Elbanna, A. R. (2007). Implementing an integrated system in a socially dis-integrated enterprise. Information Technology \& People, 20(2), 121-139. doi:10.1108/09593840710758040 
Finnegan, D., \& Currie, W. L. (2010). A multi-layered approach to CRM implementation: An integration perspective. European Management Journal, 28(2), 153-167. doi:10.1016/j.emj.2009.04.010

Finnegan, D., \& Willcocks, L. (2007). Implementing CRM: From technology to knowledge. West Sussex, UK: John Wiley \& Sons

Gersick, C., (1991). Revolutionary change theories: A multilevel exploration of the punctuated equilibrium paradigm. Academy of Management Review, 16(1), 10-36

Harris, S. G., \& Sutton, R. I. (1986). Functions of parting ceremonies in dying organizations. Academy of Management Journal, 29(1), 5-30. doi:10.2307/255857

Huber, G. P., \& Power, D. J. (1985). Retrospective reports of strategic-level managers: Guidelines for increasing their accuracy. Strategic Management Journal, 6(2), 171-180. doi:10.1002/smj.4250060206

Hung, S. Y., Hung, W. H., Tsai, C. A., \& Jiang, S. C. (2010). Critical factors of hospital adoption on CRM system: Organizational and information system perspectives. Decision Support Systems, 48(4), 592-603. doi: 10.1016/j.dss.2009.11.009

Ignatiadis, I., \& Nandhakumar, J. (2007). The impact of enterprise systems on organizational resilience. Journal of Information Technology, 22(1), 36-43. doi: 10.1057/palgrave.jit.2000087

Jasperson, J. S., Carter, P. E., \& Zmud, R. W. (2005). A comprehensive conceptualization of post-adoptive behaviors associated with information technology enabled work systems. MIS Quarterly, 29(3), 525-557. Retrieved from http://dl.acm.org

Jones, E., Sundaram, S., \& Chin, W. (2002). Factors leading to sales force automation use: A longitudinal analysis. Journal of Personal Selling \& Sales Management, 22(3), 145-156. Retrieved from www.tandfonline.com

Karahanna, E., Straub, D. W., \& Chervany, N. L. (1999). Information technology adoption across time: a cross-sectional comparison of pre-adoption and post-adoption beliefs. MIS quarterly, 23(2), 183-213. doi:10.2307/249751

Khalil, E. L. (1995). Institutional theory of the firm? Extension and limitation. Review of Political Economy, 7(1), 43-51. doi:10.1080/09538259500000003

Kim, M., Sharman, R., Cook-Cottone, C. P., Rao, H. R., \& Upadhyaya, S. J. (2012). Assessing roles of people, technology and structure in emergency management systems: A public sector perspective. Behaviour and Information Technology, 31(12), 1147-1160. doi:10.1080/0144929x.2010.510209

Klein, K. J., \& Kozlowski, S. W. (2000). Multilevel theory, research, and methods in organizations: Foundations, extensions, and new directions. San Fancisco, CA: JosseyBass

Ko, E., Kim, S. H., Kim, M., \& Woo, J. Y. (2008). Organizational characteristics and the CRM adoption process. Journal of Business Research, 61(1), 65-74. doi: 10.1016/j.jbusres.2006.05.011

Leavitt, H. J. (1964). Applied organization change in industry: Structural, technical and human approaches. New Perspectives in Organizational Research, 55-71 
Lewis, J., \& Ritchie, J. (2003). Generalising from Qualitative research. In Qualitative research practice: A guide for social science students and researchers (pp. 263-286). London, UK: Sage Publications

Luna-Reyes, L. F., Zhang, J., Gil-García, J. R., \& Cresswell, A. M. (2005). Information systems development as emergent socio-technical change: A practice approach. European Journal of Information Systems, 14(1), 93-105. doi: 10.1057/palgrave.ejis.3000524

Lyytinen, K., \& Newman, M. (2008). Explaining information systems change: A punctuated socio-technical change model. European Journal of Information Systems, 17(6), 589-613. doi:10.1057/ejis.2008.50

Lyytinen, K., Newman, M., \& Al-Muharfi, A.-R. A. (2009). Institutionalizing enterprise resource planning in the Saudi steel industry: A punctuated socio-technical analysis. Journal of Information Technology, 24(4), 286-304. doi:10.1057/jit.2009.14

MacKay, R. B., \& Chia, R. (2013). Choice, chance, and unintended consequences in strategic change: A process understanding of the rise and fall of NorthCo Automotive. Academy of Management Journal, 56(1), 208-230. doi:10.5465/amj.2010.0734

McLeod, L., \& Doolin, B. (2012). Information systems development as situated socio-technical change: A process approach. European Journal of Information Systems, 21(2), 176-191. doi:10.1057/ejis.2011.43

Merkle executive survey, 2018: 7 Must-Know CRM Adoption Statistics and What They Mean for Your CRM. Retrieved from https://www.business2community.com/customerexperience/7-must-know-crm-adoption-statistics-mean-crm-02023236

Miles, M. B., \& Huberman, A. M. (1994). Qualitative data analysis: An expanded sourcebook. London, UK: Sage

Newell, S., Tansley, C., \& Huang, J. (2002). Social Capital and Knowledge Creation in an ERP Project Team: Unintended Incapacitating Consequences of Social Capital. In 3rd European Conference on Organisational Knowledge, Learning and Capabilities. AMCIS 2001 Proceedings. 217

Newman, M., \& Robey, D. 1992. A Social Process Model of User-Analyst Relationships, MIS Quarterly, 16(2), 249-266

Patton, M. Q. (1990). Qualitative evaluation and research methods (2nd ed.). Newbury Park, CA: SAGE Publications

Rollins, G. (2012). Unintended consequences: Identifying and mitigating unanticipated issues in EHR use. Journal of AHIMA, 83(1), 28-3.

Sawyer, S., \& Southwick, R. (2002). Temporal issues in information and communication technology-enabled organizational change: Evidence from an enterprise systems implementation. The Information Society, 18(4), 263-280. doi:10.1080/01972240290075110

Schilhavy, R., \& Iyer, L. (2007). Exploring the information effects of identity and information transparency in reputation systems. Presented at the DIGIT Workshops, Montreal, Canada 
Schwartz, S. J. (2002). In search of mechanisms of change in identity development: Integrating the constructivist and discovery perspectives on identity. International Journal of Theory and Research, 2(4), 317-339. doi:10.1207/s1532706xid0204_03

Sebjan, U., Bobek, S., \& Tominc, P. (2014). Organizational factors influencing effective use of CRM solutions. Procedia Technology, 16, 459-470. doi:10.1016/j.protcy.2014.10.113

Seethamraju, R., \& Sundar, D. K. (2013). Influence of ERP systems on business process agility. IIMB Management Review, 25(3), 137-149. doi:10.1016/j.iimb.2013.05.001

Soh, C., \& Sia, S. K. (2004). An institutional perspective on sources of ERP packageorganisation misalignments. The Journal of Strategic Information Systems, 13(4), 375397. doi: 10.1016/j.jsis.2004.11.001

Srivihok, A., \& Batanov, D. (2005). Analysis of the readiness of thai SME for applying CRM. Presented at the Fourth International Conference on eBusiness, Bangkok, Thailand. Retrieved from www.ijcim.th.org

Strong, D. M., \& Volkoff, O. (2010). Understanding Organization-Enterprise system fit: A path to theorizing the information technology artifact. MIS quarterly, 34(4), 731-756. doi: $10.2307 / 25750703$

Veiga, J. F., Keupp, M. M., Floyd, S. W., \& Kellermanns, F. W. (2014). The longitudinal impact of enterprise system users' pre-adoption expectations and organizational support on post-adoption proficient usage. European Journal of Information Systems, 23(6), 691707. doi:10.1057/ejis.2013.15

Vella, J., Caruana, A., \& Pitt F., L. (2012). The effect of behavioural activation and inhibition on CRM adoption. International Journal of Bank Marketing, 30(1), 43-59. doi:10.1108/02652321211195695

Williams, S. P., \& Hardy, C. (2005). Public eProcurement as socio-technical change. Strategic Change, 14(5), 273-281. doi:10.1002/jsc.728

Williams, P., Ashill, N., \& Naumann, E. (2017). Toward a contingency theory of CRM adoption. Journal of Strategic Marketing, 25(5-6), 454-474. doi: 10.1080/0965254X.2016.1149211

Winter, S. G., \& Nelson, R. R. (1982). An evolutionary theory of economic change. Cambridge, MA: Harvard University Press

Wognum, P., Krabbendam, J., Buhl, H., Ma, X., \& Kenett, R. (2004). Improving enterprise system support: A case-based approach. Advanced Engineering Informatics, 18(4), 241253. doi:10.1016/j.aei.2005.01.007

Wu, I. L., \& Wu, K. W. (2005). A hybrid technology acceptance approach for exploring e-CRM adoption in organizations. Behaviour \& Information Technology, 24(4), 303-316. doi:10.1080/0144929042000320027

Yin, R. K. (2003). Case study research: Design and methods (3rd ed.). Thousand Oaks, CA: Sage Publications

Yoo, Y., Lyytinen, K., \& Berente, N. (2007). An institutional analysis of pluralistic responses to enterprise system implementations. Presented at the International conference on Information Systems, Montreal, Canada 
Zablah, A. R., Bellenger, D. N., \& Johnston, W. J. (2004). Customer relationship management implementation gaps. Journal of Personal Selling and Sales Management, 24(4), 279-295. Retrieved from www.tandfonline.com

Copyright: (C) 2021 authors. This is an open-access article distributed under the terms of the Creative Commons Attribution-NonCommercial 3.0 Australia License, which permits noncommercial use, distribution, and reproduction in any medium, provided the original author and AJIS are credited.

doi: https://doi.org/10.3127/ajis.v25i0.2391

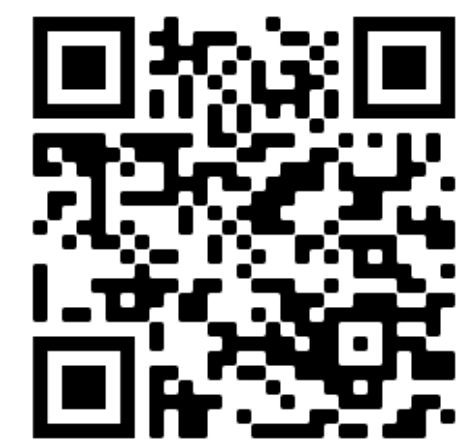

